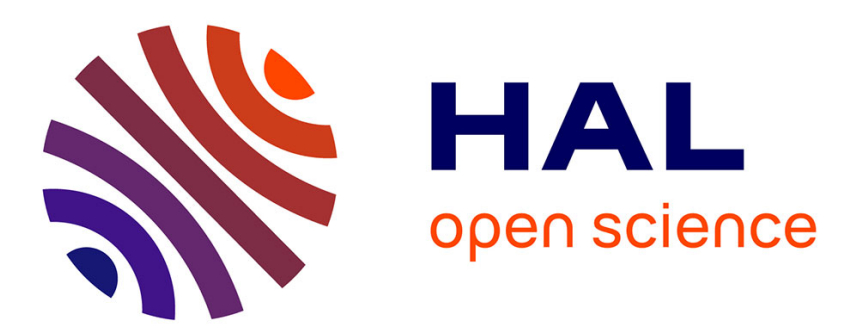

\title{
A global assessment of terrestrial alien ferns (Polypodiophyta): species' traits as drivers of naturalisation and invasion
}

Emily J Jones, Tineke Kraaij, H Fritz, D Moodley

\section{- To cite this version:}

Emily J Jones, Tineke Kraaij, H Fritz, D Moodley. A global assessment of terrestrial alien ferns (Polypodiophyta): species' traits as drivers of naturalisation and invasion. Biological Invasions, 2019, 21 (3), pp.861-873. 10.1007/s10530-018-1866-1 . hal-02334923

\section{HAL Id: hal-02334923 \\ https://cnrs.hal.science/hal-02334923}

Submitted on 7 Nov 2019

HAL is a multi-disciplinary open access archive for the deposit and dissemination of scientific research documents, whether they are published or not. The documents may come from teaching and research institutions in France or abroad, or from public or private research centers.
L'archive ouverte pluridisciplinaire HAL, est destinée au dépôt et à la diffusion de documents scientifiques de niveau recherche, publiés ou non, émanant des établissements d'enseignement et de recherche français ou étrangers, des laboratoires publics ou privés. 


\section{Biological Invasions}

\section{A global assessment of terrestrial alien ferns (Pteridophyta): species' traits as drivers of naturalisation and invasion \\ --Manuscript Draft--}

\begin{tabular}{|c|c|c|}
\hline \multicolumn{3}{|l|}{ Manuscript Number: } \\
\hline Full Title: & \multicolumn{2}{|c|}{$\begin{array}{l}\text { A global assessment of terrestrial alien ferns (Pteridophyta): species' traits as drivers } \\
\text { of naturalisation and invasion }\end{array}$} \\
\hline Article Type: & \multicolumn{2}{|l|}{ Research paper } \\
\hline Keywords: & \multicolumn{2}{|c|}{$\begin{array}{l}\text { alien ferns, global inventory, invasion stage, introduced range, native range, } \\
\text { reproductive plasticity }\end{array}$} \\
\hline Corresponding Author: & \multicolumn{2}{|l|}{$\begin{array}{l}\text { Emily Joy Jones } \\
\text { Nelson Mandela University } \\
\text { George, Western Cape SOUTH AFRICA }\end{array}$} \\
\hline \multicolumn{3}{|l|}{$\begin{array}{l}\text { Corresponding Author Secondary } \\
\text { Information: }\end{array}$} \\
\hline Corresponding Author's Institution: & \multicolumn{2}{|l|}{ Nelson Mandela University } \\
\hline \multicolumn{3}{|l|}{$\begin{array}{l}\text { Corresponding Author's Secondary } \\
\text { Institution: }\end{array}$} \\
\hline First Author: & \multicolumn{2}{|l|}{ Emily Joy Jones } \\
\hline \multicolumn{3}{|l|}{ First Author Secondary Information: } \\
\hline \multirow[t]{4}{*}{ Order of Authors: } & \multicolumn{2}{|l|}{ Emily Joy Jones } \\
\hline & \multicolumn{2}{|l|}{ Tineke Kraaij } \\
\hline & \multicolumn{2}{|l|}{ Herve Fritz } \\
\hline & \multicolumn{2}{|l|}{ Desika Moodley } \\
\hline \multicolumn{3}{|c|}{ Order of Authors Secondary Information: } \\
\hline Funding Information: & $\begin{array}{l}\text { Invasive Species Programme, South } \\
\text { African National Biodiversity Institute } \\
\text { (P010) }\end{array}$ & Miss Emily Joy Jones \\
\hline Abstract: & \multicolumn{2}{|c|}{$\begin{array}{l}\text { The global threat posed by invasive alien plants has prompted inventory compilations } \\
\text { and screening exercises that aim to understand invasiveness in various taxa. Various } \\
\text { traits influence the invasiveness of a species but do not apply indiscriminately to all } \\
\text { plant taxa. Ferns (Pteridophyta) are rare or absent from such inventories, but notable } \\
\text { fern invasions do exist. We developed a global inventory of terrestrial alien ferns } \\
\text { comprising } 157 \text { species, using published literature and online inventories. We aimed to } \\
\text { determine which traits influence the probability that a terrestrial alien fern will become } \\
\text { naturalised or invasive. Generalised linear models with transition stages as response } \\
\text { variables, were used to assess the effects of various anthropogenic, biological and } \\
\text { distributional traits on invasiveness. Our model explained } 30-40 \% \text { of the variance } \\
\text { associated with invasiveness and showed that a geophytic life form, reproductive } \\
\text { plasticity, tolerance for disturbance and varied light conditions, and a broad introduced } \\
\text { range (interpreted as high environmental tolerance and popularity in horticulture) were } \\
\text { important determinants of invasiveness in alien ferns. We highlighted which geographic } \\
\text { regions and pteridophyte families had the highest incidences of alien ferns and } \\
\text { identified particular species of concern. This study aids in the understanding of the } \\
\text { mechanisms underlying invasiveness in alien ferns and the findings can inform future } \\
\text { research on this understudied taxa as invasive species. }\end{array}$} \\
\hline Suggested Reviewers: & \multicolumn{2}{|c|}{$\begin{array}{l}\text { Klaus Mehltreter, PhD } \\
\text { Investigador Titular B, El Instuto de ecologia } \\
\text { klaus.mehltreter@inecol.mx } \\
\text { fern expert }\end{array}$} \\
\hline
\end{tabular}


Lawrence R Walker, PhD

Lecturer/ Researcher, University of Nevada Las Vegas

walker@unlv.nevada.edu

Plant ecologist interested in the mechanisms that drive primary plant succession

Neil Crouch, PhD

Biodiversity Research, South African National Biodiversity Institute

N.Crouch@sanbi.org.za

Fern expert in South Africa, keen interest in alien ferns. 
A global assessment of terrestrial alien ferns (Pteridophyta): species' traits as drivers of naturalisation and invasion

Emily J. Jones ${ }^{\mathrm{a}}$, Tineke Kraaij ${ }^{\mathrm{b}}$, Herve Fritz $^{\mathrm{c}}$, Desika Moodley ${ }^{\mathrm{d}}$

aNelson Mandela University; Madiba Dr, George Central, George, 6530, South Africa, Invasive Species Programme, South African National Biodiversity Institute,; s216016479@mandela.ac.za, +27823040264, ORCID 0000-0003-0008-6580

bNelson Mandela University; Madiba Dr, George Central, George, 6530, South Africa, Tineke.Kraaij@mandela.ac.za, +27448015018, ORCID 0000-0002-8891-2869

'Herve Fritz: Université Lyon, CNRS, UCBL, UMR 5558, Villeurbanne, 69622, France. Nelson Mandela University; SRU, Madiba Dr, George Central, George, 6530, South Africa, herve.fritz@univ-lyon1.fr, +2768041292, ORCID 0000-0002-7106-3661

${ }^{\mathrm{d}}$ Desika Moodley: Department of Invasion Ecology, Institute of Botany, Academy of Sciences of the Czech Republic, Průhonice CZ 252 43, Czech Republic, desikamoodley29@gmail.com, +420739294540

\section{$\underline{\text { Acknowledgements }}$}

This work was supported by the South African National Department of Environment Affairs through its funding of the South African National Biodiversity Institute Invasive Species Programme and by Nelson Mandela University. We thank Ronel Klopper whom extracted relevant data from the PRECIS database, and Neil Crouch for his invaluable advice and guidance. 


\begin{abstract}
The global threat posed by invasive alien plants has prompted inventory compilations and screening exercises that aim to understand invasiveness in various taxa. Various traits influence the invasiveness of a species but do not apply indiscriminately to all plant taxa. Ferns (Pteridophyta) are rare or absent from such inventories, but notable fern invasions do exist. We developed a global inventory of terrestrial alien ferns comprising 157 species, using published literature and online inventories. We aimed to determine which traits influence the probability that a terrestrial alien fern will become naturalised or invasive. Generalised linear models with transition stages as response variables, were used to assess the effects of various anthropogenic, biological and distributional traits on invasiveness. Our model explained $30-40 \%$ of the variance associated with invasiveness and showed that a geophytic life form, reproductive plasticity, tolerance for disturbance and varied light conditions, and a broad introduced range (interpreted as high environmental tolerance and popularity in horticulture) were important determinants of invasiveness in alien ferns. We highlighted which geographic regions and pteridophyte families had the highest incidences of alien ferns and identified particular species of concern. This study aids in the understanding of the mechanisms underlying invasiveness in alien ferns and the findings can inform future research on this understudied taxa as invasive species.
\end{abstract}

\title{
Keywords
}

alien ferns, global inventory, invasion stage, introduced range, native range, reproductive plasticity 


\section{Introduction}

Invasive alien species are one of the greatest threats to biodiversity, ecosystems and ecosystem services (Millennium Ecosystem Assessment 2003). Species invasion generally follows a sequence of transitions (termed the 'introduction-naturalisation-invasion continuum'; Richardson et al. 2000) from introduction (i.e. species introduced into an environment outside of its native range) to naturalisation (i.e. establishment of self-sustaining populations) to invasion (i.e. the ability to expand its range beyond the initial site of infestation/colonisation) (Falk-Petersen et al. 2006, Blackburn et al. 2011). The global significance of invasive species has prompted inventory compilations and screening exercises as a means to provide information about the mechanisms of invasion and inform sustainable management strategies, transforming the study of invasion biology into a predictive science (Latombe et al. 2017; Pyšek et al. 2017). Global inventories of alien and invasive biota are generally more comprehensive for faunal species (Pyšek et al. 2017) than for floral species. Inventories on alien flora are generally poor in species composition and are restricted in terms of geographical scale (Latombe et al. 2017).

Pteridophytes (i.e. ferns) in particular, are rare or absent from inventories on alien flora for many parts of the world. In a recent global inventory of naturalised vascular plants, ferns were absent from the list which comprised 200 of the most widely distributed naturalised plant taxa of the world (Pyšek et al. 2017). However, in a few regions alien ferns rank amongst some of the most conspicuous, ecologically damaging, and well-studied invasive species (Pemberton et al. 2002; Wilson 2002; Lott et al. 2003; Murakami et al. 2007; Chau et al. 2013). For instance, of the Florida Exotic Pest Plant Councils' (FLEPPC) list of category 1 invasive plant species (i.e. "invasive exotics that are altering native plant communities by displacing native species, changing community structures or ecological functions, or hybridizing with natives"), alien ferns comprise $12.5 \%$ of the list (FLEPPC 2017). In Florida the rapid invasion of Lygodium microphyllum (Cav.) R. Br. has infested more than 40000 ha of unique indigenous habitat (Goolsby 2004). The plants high climbing growth form allows it to fully smother forest canopies and its rapid spread is facilitated by year-round vegetative growth and spore production (Volin et al. 2004; Robinson et al. 2010).

Various anthropogenic factors and environmental and biological traits have shown to be useful predictors of species invasiveness (Kolar and Lodge 2001; Van Kleunen et al. 2010; Richardson and Pyšek 2012; Moodley et al. 2016; Miller et al. 2017). Traits such as mode of reproduction, dispersal strategy, plant height, growth rate, and environmental tolerance may provide alien plants with a competitive advantage over native species thereby facilitating invasion (Kolar and Lodge 2001). In addition, certain environmental factors (such as habitat and climate suitability, lack of competition, and presence of anthropogenic disturbance) may render an area susceptible to invasion (Terazano et al. 2018). Propagule pressure and suitability for horticulture have been found to be important determinants of invasion success (Carlton 2003; Dehnen-Schmutz et al. 2007) and relate to introduction efforts by humans exceeding a plants' natural dispersal capabilities. These effects, combined with longer residence times (time since first introduction) usually correlate with the increased likelihood of plants becoming naturalised or invasive and having larger areas of occupancy (Wilson et al. 2007; Van Kleunen et al. 2010). There are site and invasion-stage dependent effects that influence the success of naturalisation or invasion in alien plants $\mathrm{s}$ (Pyšek et al. 2012), and traits associated with invasiveness do not necessarily apply indiscriminately to all plant taxa (Dawson et al. 2009; Moodley et al. 2016). 
The majority of studies assessing invasive traits in alien plants focus on angiosperms as they are generally model plant taxon with high invasive potential (Robinson et al. 2010). Ferns differ most notably from angiosperms in terms of their reproductive systems by having two free-living generations namely gametophytes and sporophytes (de Groot et al. 2012). They reproduce by means of intergametophytic mating and recombination, or by sustaining homozygosity through intragametophytic selfing (i.e. self-fertilization of a single gametophyte) (Lloyd 1974). Intragametophytic selfing is an important characteristic to consider with regards to invasive potential in ferns because self-fertilization has been shown to be aligned with long distance colonization (Stebbins 1957). Spores are able to tolerate unfavourable aerial conditions and once established, sporophytes display a high tolerance of varying soil nutrient levels and have the ability to photosynthesise under low light conditions. Two pteridophyte genera also show gametophyte revival after desiccation or dormancy (Page 2002). Ferns furthermore pose resistance to predation, pathogens, and fungal attack through photochemical armament but benefit from plant associations through the exploitation of mycorrhizae (Richardson and Walker 2010). Various ecological and reproductive characteristics thus aid in the successful establishment of ferns in a wide range of habitats (Lott et al. 2003), and despite their evident invasive capabilities, ferns are often overlooked as an invasive taxa.

Ferns have a long evolutionary history and are diverse with more than 12000 known species. They inhabit a variety of environments but pteridophyte diversity in terms of numbers of species, genera, and families, is generally greater in regions with a higher evapotranspiration potential, annual precipitation and topographic complexity (Kessler 2010). In wet mountainous areas ferns can represent up to $13 \%$ of the local flora with ca. $60 \%$ of Pteridophytes found in the wet tropics (Amoroso 2003). In contrast, ferns are virtually absent in arid zones (with the exception of a few specifically adapted genera, e.g. Cheilanthes sp.) and are species poor in areas with Mediterranean type climates (Ferrer- Castan and Vetaas 2005). Although species distribution and richness may be influenced by environmental factors such as climate, topography and soil, fern occurrence and abundance may also be largely influenced by the dispersal ability of a species (de Groot et al. 2012), source -sink effects (Leibold et al. 2004), and anthropogenic influences (De Winter and Amoroso 2003).

Pteridophytes hold little economic value, therefore cultivation for purposes other than horticulture is unlikely (Amaroso 2003). Since the early 1800s humans have moved hundreds of species of ferns out of their natural ranges for horticultural purposes (Lowe 1864). Despite this it is estimated that globally only ca. 60 species of ferns are problematic because of their invasiveness (Robinson et al. 2010). Given their diversity, wide-ranging distribution and long horticultural history, pteridophyta seems to be a key taxon requiring systematic screening for invasiveness and assessment of traits associated with invasiveness. Our objectives were therefore to (i) develop a global inventory of terrestrial alien ferns using literature and online inventories; (ii) determine the invasion status of each species; (iii) determine which traits (i.e. including. ecological, biological and anthropogenic) influence the probability that a terrestrial alien fern will become naturalised or invasive, and (iv) highlight problematic species and families to inform future risk assessments.

\section{Methods}

Inventory, geographic distribution, and family representation 
In order to develop a global inventory of terrestrial alien ferns we surveyed various available sources which (http://www.fleppc.org) and Southern African Plaint Invaders Atlas (SAPIA); and local, regional or global online inventories (e.g. Atlas of living Australia (www.ala.org.au), Calflora (www.calflora.org), Centre for invasive species and ecosystem health (www.invasive.org), Delivering Alien Invasive Species Inventories for Europe (www.europe-aliens.org), and the Global Invasive Species Database (www.iucngisd.org). Searches were prompted using key terms such as "pteridophyte” OR “ferns” AND “alien” OR “invasive” OR “adventive” OR "naturalised" OR "non-native". Synonyms among records in our inventory were removed and only species recognised (or considerd 'unresolved') by The Plant List (www.theplantlist.org) were retained.

Species invasion status terminology has often been loosely applied in the invasion literature (Blackburn 2011). Therefore, to ensure consistency, we evaluated the accuracy and potentially modified the status of each species according the criteria of Falk-Peterson et al. (2006) and Blackburn et al. (2011). Not all records supplied comprehensive and current information, hence, some species' status may differ to that which was specified by the source. For each species we recorded information about mode of introduction but found that horticulture was the purpose for all introduced species, hence we ignored this variable in further analysis. We recorded the kingdom(s) and floristic region(s) from which a species was donated, and floristic region(s) to which it was introduced (kingdoms and regions follow Takhtajan 1986).

To gain an understanding of the geographic distribution of alien ferns, we assessed the frequency distribution of alien species in terms of their native floristic regions and introduced floristic regions. We also collected information on several ecological and biological attributes (Table 1) for each species using scientific literature, online databases, field identification guides, compendiums, and open source websites (Supplementary 1). In similar studies it is common practice to control for phylogenetic constraints (Grotkopp and Rejmánek 2007, Moodley et al. 2016, Pyšek and Richardson 2008). However, phylogenetic relationships among existing and fossil pteridophytes remain largely unresolved (Hennequin 2017, Wolf 1998) and is further constrained by the lack of information surrounding primitive or advanced character states (Roux 2001). To assess the prevalence of alien fern species in relation to family size we calculated for each family the proportion of the total number of accepted species in that family (according to The Plant List) that have been introduced outside their native range. To assess whether alien species are overrepresented in certain families we then compared the proportion of each family that is alien to the proportion that is alien for Pteridophyta as a whole.

\section{Analysis of traits influencing invasiveness}

We used generalised linear models (GLMs) with binomial response variables to assess which traits (i.e. explanatory variables, Table 1) are associated with invasion status (i.e. response variables; hereafter referred to as 'status'). The modelled logistic function predicts the probability of changing status for a given set of traits. Since the relative importance of traits affecting invasiveness differs amongst the stages of invasion (Richardson \& Pyšek 2012), we estimated the status change from (i) introduced to naturalised (transition one), (ii) naturalised to invasive (transition two), or (iii) introduced to invasive (transition three), with each transition coded as a binary response variable. The first transition along the introduction-naturalisation-invasion continuum (Richardson et al. 2000) could not be assessed as all native (i.e. non-alien) pteridophytes could not 
considered in this study given the size of the taxon. Instead we included transition three (introduced to invasive) in order to augment the size of the dataset for analysis of traits contributing to invasiveness.

Table 1. Explanatory variables and interactions considered in the assessment of traits potentially associated with invasiveness in alien ferns

\section{[Insert Table 1]}

Prior to running the GLMs, we tested for collinearity between explanatory variables using Pearson's correlation coefficient (Supplementary 2). We used r=0.6 as the cut-off point to jointly include variables in a model (Dall 2000). Number of native regions and number of native kingdoms were highly correlated. We first included number of native regions (and not number of native kingdoms) in our models as it has often been a significant predictor in similar studies (Moodley et al. 2013, 2016). However, number of native regions never contributed significantly, hence we rather retained number of native kingdoms.

We used the output of the analysis of variance (ANOVA) to re-order the variables and relationships within the models from most significant to least significant. A manual backwards stepwise selection procedure was used to gradually remove the non-significant $(\mathrm{P}>0.05)$ variables, starting with the interaction terms. Variables and significant interactions were kept in the model even if they showed nonsignificant single effects. In such models, the order of the explanatory variables can have consequences on the remaining deviance explained by subsequent variables, hence their significance. Therefore, building several models and reordering variables enables robust conclusions. This also enabled us to test for the effect of variables that could be masked by partial correlation (i.e. weak collinearity). Furthermore, other studies have shown that, building hierarchical models allows for testing specific variables (Moodley et al. 2016; Pyšek et al. 2017). In our case, we forced residence time and number of introduced regions to be in our initial models as they have shown to have significant effects in previous studies (Wilson et al. 2007; Moodley et al. 2016). Ultimately, we fitted a logistic regression model using the backwards manual stepwise procedure to four potential initial models.

To further test the robustness of our results, the same process was then repeated using a manual forward stepwise selection procedure, and the function 'stepAIC' from package 'MASS' (Venables and Ripley 2002) and using both a backward and forward procedure. This ensured that no variables potentially explaining deviance were missed in the manual backwards selection procedure. The variables identified in these procedures were consistent across models and therefore, for simplicity and ease of discussion, we only presented the results of the manual backwards procedure. Since we aimed to build a usable (i.e. simple) predictive model, we selected the models with a high explanatory power but with the least number of significant variables necessary to explain the probability of becoming naturalised or invasive. A model that is more biologically comprehensive and information-laden is likely to explain a greater proportion of the deviance but would be constrained by the availability of information on various species. To assess the predictive power of the final selected models we considered McFadden's R squared values for logistic regression. The final model was used to calculate and plot the probability of an alien fern becoming naturalised or invasive. All analyses were conducted with the open source R software (version 1.1.383) (R Development Core Team 2017).

\section{Results}


The inventory comprised 157 species of alien ferns (Supplementary 1), which is ca. 0.02\% of the 10620 recognised species of ferns. In terms of invasion status, $12 \%$ of the recorded species were introduced but not naturalised, 49\% were naturalised but not invasive, and 39\% were invasive. Geographic distribution of donated and received fern species at the scale of floristic kingdoms suggests little latitudinal constraint (Fig. 1). At the scale of floristic regions (FR) some patterns were evident. The Eastern Asiatic (FR 2) and Irano-Turanian (FR 8) donated the greatest numbers of species whereas few species originated from the Mediterranean (FR 6), Indian (FR 16), and the Indochinese (FR 17). Regions which received the most species were the Neozeylandic (FR 35), Hawaiian (FR 21), and Circumboreal (FR 1), and although FRs 2 and 8 donated many species, they received few species. Specific species of concern that were shown to be invasive over extensive introduced ranges include Lygodium japonicum (Thunb.) Sw., Lygodium microphyllum (Cav.) R. Br., Adiantum raddianum C. Presl, Angiopteris evecta (G. Forst) Hoffm, Cyrtomium falcatum (L. f.) C. Presl, Macrothelypteris torresiana (Gaudich.) Ching., Nephrolepis cordifolia (L.) C. Presl, Phlebodium aureum (L.) J. Sm., Pityrogramma calomelanos (L.) Link, Pteris vittata L., and Sphaeropteris cooperi (F. Muell.) R.M. Tryon.

\section{[Insert Figure 1]}

Fig. 1 Numbers of alien fern species donated by native floristic regions (grey circles) and received by introduced floristic regions (black circles). The 35 floristic regions of the world fall into 6 floristic kingdoms (based on Takhtajan (1986)). The size of the circle corresponds to number of species

Twenty-four families were represented by alien fern species. Alien species comprised $0.02 \%$ of all recognised fern species. Families within which alien species were overrepresented relative to their size included the Psilotaceae, Nephrolepidaceae, Equisetaceae, Onocleaceae and Lygodiaceae (Fig. 2). In terms of absolute numbers of alien species contributed, Pteridaceae (37 species), Dryopteridaceae (21 species), Blechnaceae (12 species), Polypodiaceae (11 species), and Dennstaedtiaceae (11 species) ranked the highest (Fig. 2).

[Insert Figure 2]

Fig. 2 The prevalence of alien fern species in relation to family size (number of species), calculated as the proportion of the total number of species that are alien within each family, as well as for Pteridophyta as a whole (respectively)

\section{Traits influencing invasiveness}

The final model for the transition from introduced to naturalised (transition one) retained the variables mode of regeneration and number of introduced regions; for the transition from naturalised to invasive (transition two), number of introduced regions, light, life form, and disturbed habitat; and for the transition from introduced to invasive (transition three), number of introduced regions, light, disturbed habitat, number of native kingdoms, and mode of regeneration (Table 2; Fig. 3). Growth form, wet habitat, and residence time had no significant effect. The McFadden's R squared values for logistic regression showed the variation explained by our models to be 30 $\%$ for transition one, $30 \%$ for transition two, $40 \%$ for transition three. 
Number of introduced regions significantly increased probability of species becoming naturalised or invasive. The

\section{Discussion}

\section{Family and geographic representation}

Our global inventory of alien ferns showed that there are significantly more alien species (157) than the ca. 60 species noted by Robinson et al. (2010). An estimated 3.9\% of the global vascular flora have naturalised or become invasive (van Kleunen et al. 2015) which is a significantly higher proportion than what we found for terrestrial ferns $(0.02 \%$ are alien of which half have naturalised or become invasive). However, due to the poor recording of pteridophytes and their invasion status in inventories, there are likely to be more alien fern species than we recorded. In fact, a fern is likely to be noted only once it has become an established and ecologically damaging invader (Amoroso 2003), which likely explains the underrepresentation of introduced species in our study

Similar studies screening for invasiveness identified a strong relationship between invasion status and the extent of the species' native and introduced ranges (Rejmanek and Richardson 1996; Pyšek et al. 2009; Moodley et al. 2013; Moodley et al. 2016; Latombe et al. 2017). Similarly, in our study number of introduced regions had a significant effect on species at each stage of transition, and species with a higher number of native kingdoms showed a greater probability of becoming invasive than those with a smaller native range. In general, climate, species specific ecological requirements, ease of dispersal and the availability of suitable habitat largely determine the distribution of fern species (Lester et al. 2009). In our study however, the geographical distribution of donated and received species (Fig.1) appears to have been determined largely by anthropogenic influences as no particular longitudinal patterns are evident. Furthermore, all species were introduced for horticultural purposes. Floristic regions with large numbers of donated or received fern species typically had (i) an overrepresentation of alien or invasive plants generally (e.g. on islands such as England, New Zealand and Hawaii; Vernon and Ranker 2013); (ii) well-studied alien fern invasions (e.g. Hawaii, FR 21; Wilson 2002); (iii) many native fern species with horticultural value (e.g. Southeast Asia, FR 2 and 8; Amoroso 2003); and (iv) long histories of horticultural introductions (e.g. Britain, FR 1; Smith 1895).

Ferns are selected in horticulture for their full foliage appearance, compact size, evergreen habit, unique characteristics (colour, texture or shape), high reproductive ability, fast growth rate, and high environmental tolerance (Amoroso 2003). Plant traits that are popular in horticulture often facilitate the invasiveness of a species 
(Dehnen-Schmutz et al. 2007). In our inventory of alien ferns, families within which aliens were overrepresented often had species that were invasive over extensive introduced ranges and were popular in horticulture (Fig. 2; Supplementary1). The recorded families generally concur with those suggested by horticultural plant guides, e.g. Young (1996) listed species from the families Pteridaceae, Blechnaceae, Davalliaceae, Dennstaedtiaceae, Nephrolepidaceae, and Lygodiaceae; and species such as Lygodium japonicum (Thunb.) Sw., Lygodium microphyllum (Cav.) R. Br., Angiopteris evecta (G. Forst) Hoffm., Pteris vittata L., and Sphaeropteris cooperi (F. Muell.) R.M. Tryon. were identified as species of concern in our study but have also previously been identified as serious invaders (Robinson et al. 2010).

Our study supports the notion that progression along the introduction-naturalisation-invasion continuum is mediated by stage-dependant traits (Richardson and Pyšek 2012; Moodley 2016). The general likelihood of an alien fern species to become naturalised or invasive once introduced was high (Fig. 3) compared to what is known for other taxa (Williamson and Fitter 1996). Alien ferns have an $80 \%$ chance of becoming naturalised if they possess the ability to regenerate both sexually and vegetatively. Mode of regeneration is often a significant predictor of invasive success in various species (Kolar and Lodge 2001) but is not necessarily a consistent predictor across all taxa. In Proteaceae, invasiveness was related to regeneration mode where resprouters were more likely to naturalise while reseeders were more likely to invade (Moodley et al. 2013), but no relationship was evident in Araceae (Moodley et al. 2016). The combination of multiple reproductive modes and the ability to occupy sun-exposed sites are dual traits shared by many invasive fern species (Robinson et al. 2010; Arosa et al. 2012). Higher light conditions/ availability can enable faster growth rates which in turn should increase invasiveness, whereas shaded environments can limit the spread of various fern species (Mehltreter and Sharpe 2013). Accordingly, the ability to survive under all light forms or high light conditions (e.g. the highly invasive Angiopteris evecta (G. Forst.) in Hawaii, Christenhusz 2008) increased the probability of alien ferns becoming invasive, whereas strictly shade-loving species held a lower potential for invasiveness. Furthermore, ferns that have characteristics which allow them to survive in habitats of low nutrients and high-light conditions are bestt adapted to grow in disturbed areas (Walker and Sharpe 2010).

Disturbance, especially those caused by human activities (e.g. landslides, cliffs, roads and railways, fire regimes, and plantations) commonly promotes the spread and proliferation of invasive plants and generally reduces resistance to invasion by intact native communities (Richardson et al. 2011; Baard and Kraaij 2014; Terzano et al. 2018; Hobbs and Huenneke 1992). In our study disturbance facilitated the transition from naturalised to invasive in alien fern species, similarly Robinson et al. (2010) and Walker and Sharpe (2010) found that disturbance promoted invasive behaviour in alien ferns by increasing growth and subsequent regeneration. Ferns thrive in urban environments and can establish successfully in and on manmade surfaces such as the under hangs of bridges, old cracked walls, and drainage canals (Morajkar et al. 2015). In South Africa, Sphaeropteris cooperi (F. Muell.) R.M. Tryon. occurs in higher densities in commercial timber plantations (associated with disturbance) than in undisturbed indigenous forest (E Jones, unpublished data).

We found that ferns with a geophytic life form, rather than epiphytic or lithophytic, were more likely to become invasive. Similarly, geophytic ferns accounted for most of the invasive fern species recorded in Hawaii, whereas 
very few were epiphytic (Robinson et al. 2010; Wilson 2002). In contrast to geophytes, epiphytes are generally limited by the availability of the particular surfaces on which they grow and are more likely to be exposed to water stress because they are rooted in shallower substrates (Mehltreter and Sharpe 2013). However, exceptions do exist, for instance Platycerium bifurcatum (Cav.) C. Chr. grows in large colonies in its native (Pemberton 2003) and invaded (EJJ pers. obs.) habitat, where it is able to form extensive chains within a single tree and commonly spreads to trees adjacent to the parent population. Just as certain geophytic species may depend on particular soil characteristics, so too do epiphytic and lithophytic species depend on the particular characteristics of their host substrate (Mehltreter et al 2010) therefore a greater understanding of how environmental factors influence richness amongst fern life forms is needed (Richardson and Walker, 2010).

Propagule pressure is another significant predictor of invasiveness in various plant taxa (Colautti 2006) and involves the number of reproductive propagules and the rate at which they arrive in an area per unit time (Williamson 1996; Simberloff 2009). Some studies screening for invasiveness used several measures as a proxy for propagule pressure, one of which is the number of introduced regions (Colautti et al. 2006; Zenni and Simberloff 2013; Moodley et al. 2016). Although introductions of a species across numerous floristic regions may in some cases concur with extensive introduction efforts within a region (and as such serve as a proxy for propagule pressure), this relation cannot be assumed, particularly at the scale of global floristic regions. We argued that the introduction of a species within one floristic region cannot facilitate invasion of that species in another floristic region and rather interpreted number of introduced regions, and number of native kingdoms (at yet a larger spatial scale), as proxies for environmental tolerance (cf. Denehen-Schmutz et al. 2007). In our study, a larger number of native kingdoms significantly promoted the transition to invasive suggesting that high environmental tolerance in ferns increases their invasive potential.

Additional factors that could not be assessed in this study include aspects such as such as leaf life span (Mehltreter and Sharpe 2013), frond size, plant size, growth rate, spore load and longevity (Durand and Goldstein 2001), the ability to alter soil function (Chau et al. 2013), the use of chemical defence, and the presence of natural enemies or predators (Robinson et al. 2010). These traits were considered in other studies on invasive ferns and are traits displayed by popular horticultural species, they are likely to influence invasiveness in alien ferns and warrant further investigation. Furthermore, gametophytes and sporophytes exist separately and their ecological requirements for survival differ (Sharpe et al. 2010) for e.g. gametophytes of some species have been recorded as being more stress tolerant (Sato and Sakai 1981) and inhabiting areas inhospitable (Peck et al. 1990) to their sporophyte form. The manner in which disparate requirements of these different life stages affect species' distribution ranges or their invasive potential have not yet been explored but may further explain distribution and invasiveness in alien ferns (Sharpe et al. 2010).

\section{Conclusion}

Our model explained $30-40 \%$ of the variance associated with invasiveness in terrestrial alien ferns and highlighted that a geophytic life form, reproductive plasticity, tolerance for disturbance and varied light conditions, and a broad introduced range (hence a high environmental tolerance and popularity in horticulture) are important determinants of invasiveness. Furthermore, our study supported that there are invasion-stage dependant effects, whereby a trait or set of traits becomes important during different invasion stages (Pyšek et al. 2009). We found 
that some mechanisms driving invasiveness in alien ferns are similar to those in other taxa, e.g. thriving under high light conditions and disturbance (Richardson and Pyšek 2012). Horticulture is a well-documented driver of invasiveness in various alien species (Dehnen-Schmutz et al. 2007) and appeared to have been highly influential in the spread and successful establishment of alien ferns, supported by the significant influence of number of introduced regions as a predictive variable. Terrestrial ferns have to date been largely overlooked as a likely invasive taxon, but this study showed that some ferns have high invasive potential. We identified additional biological traits of ferns that may influence invasiveness and warrant further study. Divergent ecological requirements and tolerances of the two life stages (gametophyte and sporophyte) of ferns may be of particular importance in their invasion success. In conclusion, this study initiated the identification of traits associated with invasiveness in ferns and highlighted aspects that require further investigation. 
Conflict of Interest: The authors declare that they have no conflict of interest.

1

2

3

4

5

7

8

9

10

13

14

15

16

17

18

19

20

21

22

23

24

25

26

27

28

29

30

31

32

33

34

35

36

37

38

39

40

41

42

43

44

45

46

47

48

49

50

51

52

53

54

55

56

57

58

59

60

61

62

63

64

65 


\section{References}

Arosa, M. L., R. S. Ceia, L. G. Quintanilla, and J. A. Ramos. 2012. The tree fern Dicksonia antarctica invades two habitats of European conservation priority in São Miguel Island, Azores. Biological invasions 14:1317-1323.

Baard, J. and T. Kraaij. 2014. Alien flora of the Garden Route National Park, South Africa. South African Journal of Botany 94:51-63.

Bajwa, A. A., B. S. Chauhan, M. Farooq, A. Shabbir, and S. W. Adkins. 2016. What do we really know about alien plant invasion? A review of the invasion mechanism of one of the world's worst weeds. Planta 244:39-57.

Blackburn, T. M., P. Pyšek, S. Bacher, J. T. Carlton, R. P. Duncan, V. Jarošík, J. R. Wilson, and D. M. Richardson. 2011. A proposed unified framework for biological invasions. Trends in ecology \& evolution 26:333339.

Boughton, A. J. and R. W. Pemberton. 2009. Establishment of an imported natural enemy, Neomusotima conspurcatalis (Lepidoptera: Crambidae) against an invasive weed, Old World climbing fern, Lygodium microphyllum, in Florida. Biocontrol Science and Technology 19:769-772.

Carlton, J. 2003. Invasive species: vectors and management strategies. Island Press, Washington D.C. ISBN 155963-902-4.

Chau, M. M., L. R. Walker, and K. Mehltreter. 2013. An invasive tree fern alters soil and plant nutrient dynamics in Hawaii. Biological invasions 15:355-370.

Colautti, R. I., I. A. Grigorovich, and H. J. MacIsaac. 2006. Propagule pressure: a null model for biological invasions. Biological invasions 8:1023-1037.

Dawson, W., D. F. Burslem, and P. E. Hulme. 2009. Factors explaining alien plant invasion success in a tropical ecosystem differ at each stage of invasion. Journal of Ecology 97:657-665.

de Groot, G. A., B. Verduyn, E. J. Wubs, R. H. Erkens, and H. J. During. 2012. Inter-and intraspecific variation in fern mating systems after long-distance colonization: the importance of selfing. BMC Plant Biology $12: 3$.

de Winter, W. and V. Amoroso. 2003. Cryptogams: ferns and fern allies. Plant resources of South East Asia. Backhuys publishers 15 (2).

Dehnen-Schmutz, K., J. Touza, C. Perrings, and M. Williamson. 2007. The horticultural trade and ornamental plant invasions in Britain. Conservation Biology 21:224-231.

Durand, L. Z. and G. Goldstein. 2001. Growth, leaf characteristics, and spore production in native and invasive tree ferns in Hawaii. American Fern Journal 91:25-35.

Falk-Petersen, J., T. Bøhn, and O. T. Sandlund. 2006. On the numerous concepts in invasion biology. Biological invasions 8:1409-1424.

Ferrer- Castán, D. and O. R. Vetaas. 2005. Pteridophyte richness, climate and topography in the Iberian Peninsula: comparing spatial and nonspatial models of richness patterns. Global Ecology and Biogeography 14:155165.

FLEPPC. 2017. List of Florida's Invasive Plant Species. URL: http://www.fleppc.org.

Ghazoul, J. 2002. Flowers at the front line of invasion? Ecological entomology 27:638-640.

Goolsby, J.A., 2004. Potential distribution of the invasive Old World climbing fern, Lygodium microphyllum in North and South America. Natural Areas Journal, 24(4), pp.351-353.

Grotkopp, E. \& Rejmánek, m. 2007. High seedling relative growth rate and specific leaf area are traits of invasive species: phylogenetically independent contrasts of woody angiosperms. American Journal of Botany, 94, 526-532.

Guo, Q., M. Kato, and R. E. Ricklefs. 2003. Life history, diversity and distribution: a study of Japanese pteridophytes. Ecography 26:129-138.

Hennequin, S., Rouhan, G., Salino, A., Duan, Y.-F., Lepeigneux, M.-C., Guillou, M., Ansell, S., Almeida, T. E., Zhang, L.-B. \& Schneider, H. 2017. Global phylogeny and biogeography of the fern genus Ctenitis (Dryopteridaceae), with a focus on the Indian Ocean region. Molecular phylogenetics and evolution, 112, 277-289.

Hobbs, R. J. and L. F. Huenneke. 1992. Disturbance, diversity, and invasion: implications for conservation. Conservation Biology 6:324-337.

Kessler, M. 2010. Biogeography of ferns. Fern ecology. Cambridge University press. p22-60.

Kolar, C. S. and D. M. Lodge. 2001. Progress in invasion biology: predicting invaders. Trends in ecology \& evolution 16:199-204.

Latombe, G., P. Pyšek, J. M. Jeschke, T. M. Blackburn, S. Bacher, C. Capinha, M. J. Costello, M. Fernández, R. D. Gregory, and D. Hobern. 2017. A vision for global monitoring of biological invasions. Biological Conservation 213:295-308. 
Leibold, M. A., M. Holyoak, N. Mouquet, P. Amarasekare, J. M. Chase, M. F. Hoopes, R. D. Holt, J. B. Shurin,

Lott, M. S., J. C. Volin, R. W. Pemberton, and D. F. Austin. 2003. The reproductive biology of the invasive ferns Lygodium microphyllum and L. japonicum (Schizaeaceae): implications for invasive potential. American Journal of Botany 90:1144-1152.

Medeiros, A., L. Loope, T. Flynn, S. Anderson, L. Cuddihy, and K. Wilson. 1992. Notes on the status of an invasive Australian tree fern (Cyathea cooperi) in Hawaiian rain forests. American Fern Journal 82:2733.

Mehltreter, K. and J. Sharpe. 2013. Causes and consequences of the variability of leaf lifespan of ferns. Fern Gaz 19:193-202.

Miller, J. T., C. Hui, A. H. Thornhill, L. Gallien, J. J. Le Roux, and D. M. Richardson. 2017. Is invasion success of Australian trees mediated by their native biogeography, phylogenetic history, or both? AoB Plants 9.

Moodley, D., S. Geerts, D. M. Richardson, and J. R. Wilson. 2013. Different traits determine introduction, naturalization and invasion success in woody plants: Proteaceae as a test case. PLoS One 8:e75078.

Moodley, D., Ş. Procheş, and J. R. Wilson. 2016. A global assessment of a large monocot family highlights the need for group-specific analyses of invasiveness. AoB Plants 8.

Morajkar, S., S. Sajeev, and S. Hegde. 2015. Ferns: a thriving group of Urban dwellers. Bionature 35:13-21.

Murakami, K., R. Matsui, and Y. Morimoto. 2007. Northward invasion and range expansion of the invasive fern Thelypteris dentata (Forssk.) St. John into the urban matrix of three prefectures in Kinki District, Japan. American Fern Journal 97:186-198.

Peck, J. H., C. J. Peck and D. R. Farrar. 1990. Influences of life history events on the formation of local and distant fern populations. American Fern Journal 80: 126-42.

Pemberton, R., J. Goolsby, and A. Wright. 2002. Old World climbing fern. Biological control of Invasive Plants in the Eastern United States. Forest Health Technology Enterprise Team 10:139-147

Pemberton, R. W. 2003. The common staghorn fern, Platycerium bifurcatum, naturalizes in southern Florida. American Fern Journal 93:203-206.

Pyšek, P., V. Jarošík, P. E. Hulme, J. Pergl, M. Hejda, U. Schaffner, and M. Vilà. 2012. A global assessment of invasive plant impacts on resident species, communities and ecosystems: the interaction of impact measures, invading species' traits and environment. Global Change Biology 18:1725-1737.

Pyšek, P., M. Křivánek, and V. Jarošík. 2009. Planting intensity, residence time, and species traits determine invasion success of alien woody species. Ecology 90:2734-2744.

Pyšek, P., J. Pergl, F. Essl, B. Lenzner, W. Dawson, H. Kreft, P. Weigelt, M. Winter, J. Kartesz, and M. Nishino. 2017. Naturalized alien flora of the world. Preslia. 89:203-274.

Pyšek, P. \& Richardson, D. M. 2008. Traits associated with invasiveness in alien plants: where do we stand? Biological invasions. Springer.

R Core Team (2013). R: A language and environment for statistical computing. R Foundation for Statistical Computing, Vienna, Austria. URL http://www.R-project.org/.

Rejmánek, M. and D. M. Richardson. 1996. What attributes make some plant species more invasive? Ecology 77:1655-1661.

Richardson, D. M., J. Carruthers, C. Hui, F. A. Impson, J. T. Miller, M. P. Robertson, M. Rouget, J. J. Le Roux, and J. R. Wilson. 2011. Human- mediated introductions of Australian acacias-a global experiment in biogeography. Diversity and distributions 17:771-787.

Richardson, D. M. and P. Pyšek. 2012. Naturalization of introduced plants: ecological drivers of biogeographical patterns. New Phytologist 196:383-396.

Richardson, D. M., P. Pyšek, M. Rejmánek, M. G. Barbour, F. D. Panetta, and C. J. West. 2000. Naturalization and invasion of alien plants: concepts and definitions. Diversity and distributions 6:93-107.

Richardson, S. \& Walker, L. 2010. Nutrient ecology of ferns. Fern ecology. Cambridge University Press, Cambridge, 111-139.

Robinson, R., E. Sheffield, and J. Sharpe. 2010. Problem ferns: their impact and management. Pages 255-322. Cambridge University Press: Cambridge, UK.

Roux, J. P. 2001. Conspectus of Southern African Pteridophyta: An Enumeration of the Pteridophyta of Angola, Botswana, Lesotho, Malawi, Mozambique, Namibia, South Africa (including the Marion Island Group), Swaziland, Zambia and Zimbabwe. Southern African Botanical Diversity Network Report

Sato, T. and A. Sakai. 1981. Cold tolerance of gametophytes and sporophytes of some col temperature ferns native to Hokkaido. Canadian Journal of Botany 59: 604- 608.

Sakai, A. K., F. W. Allendorf, J. S. Holt, D. M. Lodge, J. Molofsky, K. A. With, S. Baughman, R. J. Cabin, J. E. Cohen, and N. C. Ellstrand. 2001. The population biology of invasive species. Annual review of ecology and systematics 32:305-332. 
Sharpe, J. M., K. Mehltreter, and L. R. Walker. 2010. Ecological importance of ferns. Fern ecology. Cambridge University press.

Smith, J. 1895. Ferns: British \& Foreign. London: Robert Hardwicke, 192, Piccadilly. 1886.

Terzano, D., I. Kotzé, C. Marais, S. Cianciullo, A. Farcomeni, P. Caroli, L. Malatesta, and F. Attorre. 2018. Environmental and anthropogenic determinants of the spread of alien plant species: insights from South Africa's quaternary catchments. Plant Ecology:1-21.

Tryon, R. 1986. The biogeography of species, with special reference to ferns. The Botanical Review 52:117-156.

Van Kleunen, M., E. Weber, and M. Fischer. 2010. A meta- analysis of trait differences between invasive and non- invasive plant species. Ecology letters 13:235-245.

Venables, W. N. \& Ripley, B. D. (2002) Modern Applied Statistics with S. Fourth Edition. Springer, New York. ISBN 0-387-95457-0

Vernon, A. L. and T. A. Ranker. 2013. Current status of the ferns and lycophytes of the Hawaiian Islands. American Fern Journal 103:59-111.

Volin, J. C., M. S. Lott, J. D. Muss, and D. Owen. 2004. Predicting rapid invasion of the Florida Everglades by Old World climbing fern (Lygodium microphyllum). Diversity and distributions 10:439-446.

Walker, L. R. and J. M. Sharpe. 2010. Ferns, disturbance and succession. Fern ecology:177-219.

Williamson, M. and Fitter, A., 1996. The varying success of invaders. Ecology, 77(6), pp.1661-1666.

Wilson, J. R., D. M. Richardson, M. Rouget, Ş. Procheş, M. A. Amis, L. Henderson, and W. Thuiller. 2007. Residence time and potential range: crucial considerations in modelling plant invasions. Diversity and distributions 13:11-22.

Wilson, K. A. 2002. Continued pteridophyte invasion of Hawaii. American Fern Journal 92:179-183.

Wolf, P. G., Pryer, K. M., Smith, A. R. \& Hasebe, M. 1998. Phylogenetic studies of extant pteridophytes. Molecular systematics of plants II. Springer.

Zenni, R. D. and D. Simberloff. 2013. Number of source populations as a potential driver of pine invasions in Brazil. Biological invasions 15:1623-1639. 


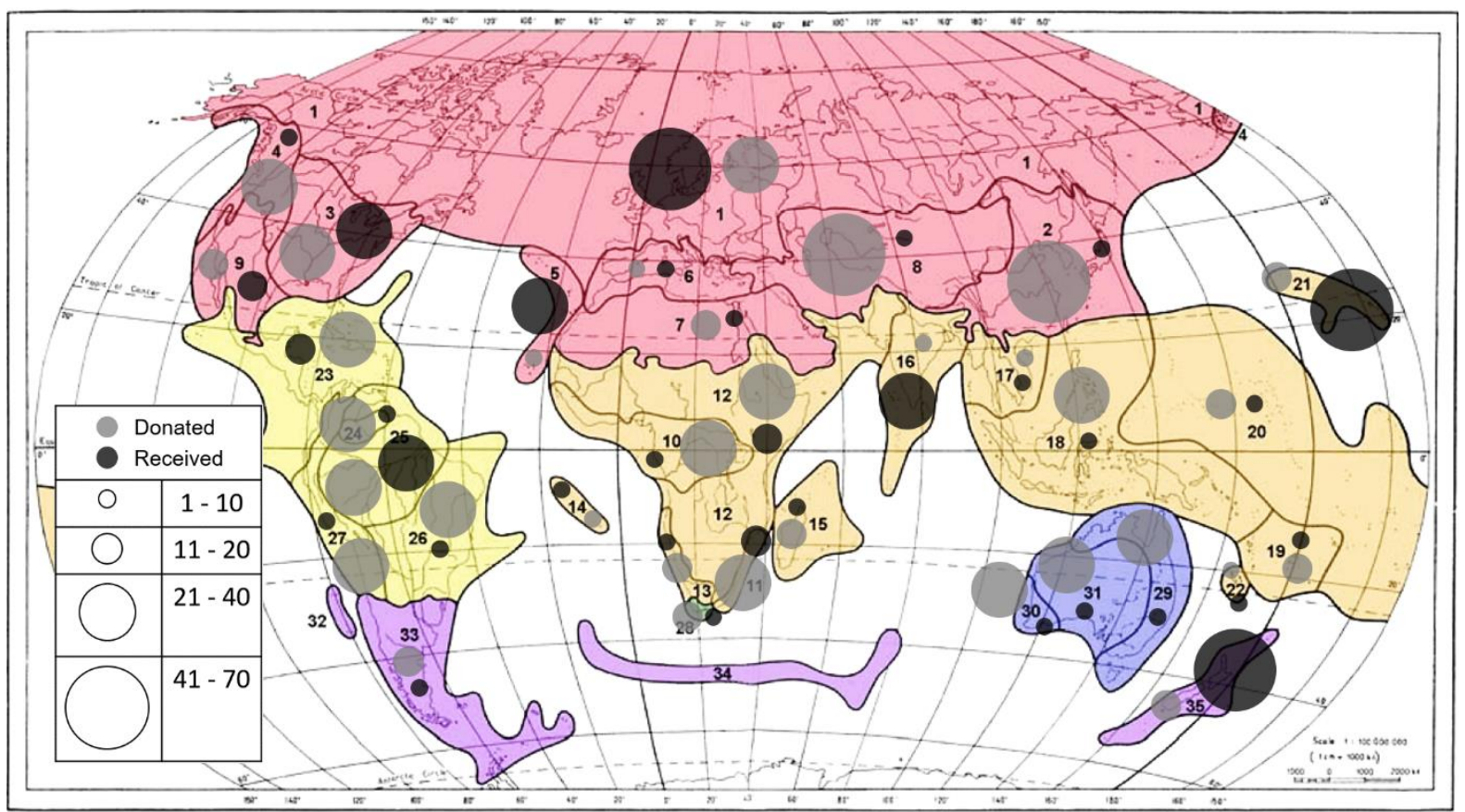

Fig. 1 Numbers of alien fern species donated by native floristic regions (grey circles) and received by introduced floristic regions (black circles). The 35 floristic regions of the world fall into 6 floristic kingdoms (based on Takhtajan (1986)). The size of the circle corresponds to number of species 


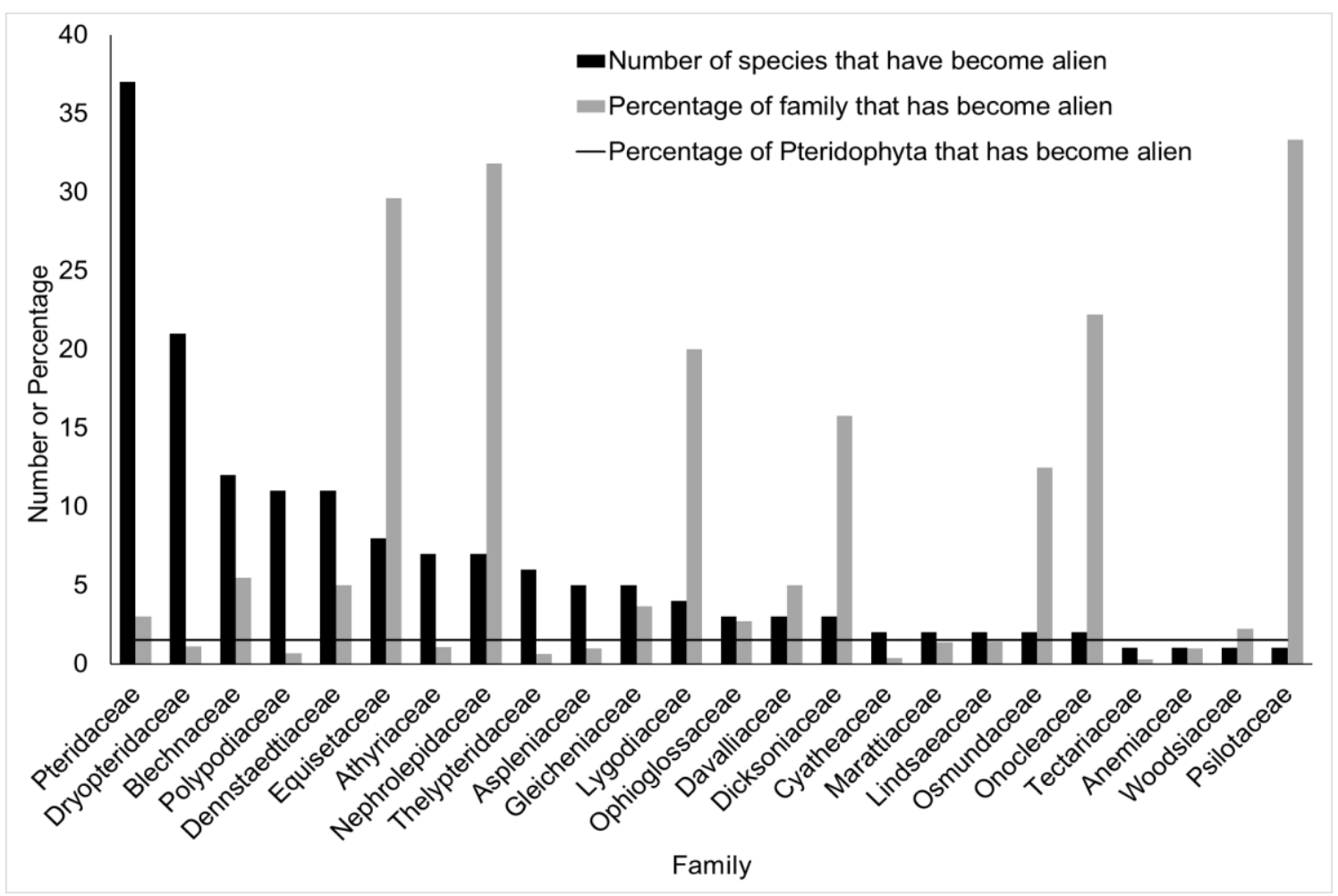

Fig. 2 The prevalence of alien fern species in relation to family size (number of species), calculated as the proportion of the total number of species that are alien within each family, as well as for Pteridophyta as a whole (respectively) 

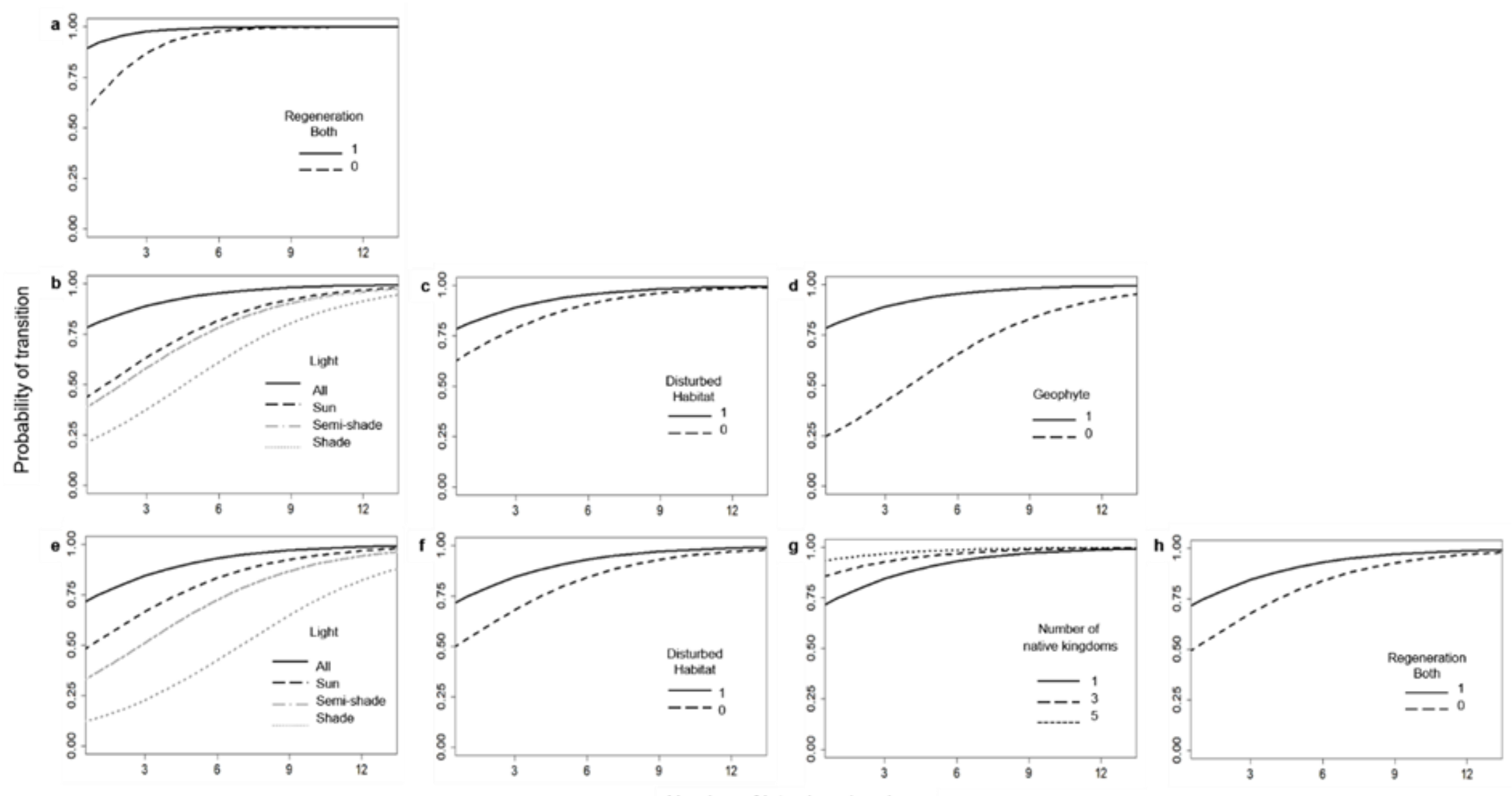

Fig. 3 The relative probability of an alien fern species transitioning from (a) introduced to naturalised (transition one), (b-d) naturalised to invasive (transition two), or (e-h) introduced to invasive (transition three) for significant variables (details in Table 1) in relation to the effect of number of introduced regions as it was always significant. We fixed model variables not displayed in each graph to their intercept values to better describe the relative probabilities associated with the variations of the variable displayed in addition to number of introduced regions. For binary variables, 1's and 0's follow the descriptions provided in Table 1. 
Table 1. Explanatory variables and interactions considered in the assessment of traits potentially associated with invasiveness in alien ferns

\begin{tabular}{|c|c|c|c|}
\hline Trait & Variable type & No. of modalities & Explanation \\
\hline Mode of regeneration & Categorical & 2 & $\begin{array}{l}\text { (1) Adopts both methods of reproduction } \\
\text { (vegetative and sexual) / }(0) \text { only adopts one } \\
\text { method (vegetative or sexual) }\end{array}$ \\
\hline Life form & Categorical & 2 & $\begin{array}{l}\text { (1) Geophytic (soil substrate) / (0) epiphytic } \\
\text { (arboreal substrate) or lithophytic (rock or } \\
\text { stone substrate) }\end{array}$ \\
\hline Growth form & Categorical & 2 & $\begin{array}{l}\text { (1) Rhizomal / (0) arborescent (e.g. tree } \\
\text { fern) }\end{array}$ \\
\hline Wet habitat & Categorical & 2 & $\begin{array}{l}\text { (1) Preference for wet habitats (wetlands, } \\
\text { streams, etc.) / (0) preference for drier } \\
\text { habitats }\end{array}$ \\
\hline Disturbed habitat & Categorical & 2 & $\begin{array}{l}\text { (1) Preference for disturbed habitats (e.g. } \\
\text { roadsides or plantation) / ( } 0 \text { ) preference for } \\
\text { undisturbed habitat }\end{array}$ \\
\hline Light & Categorical & 4 & $\begin{array}{l}\text { Species occurs primarily in: } \\
\text { full sun / } \\
\text { full shade / } \\
\text { semi-shade / } \\
\text { all light forms }\end{array}$ \\
\hline $\begin{array}{l}\text { Number of native regions } \\
\text { (proxy for environmental } \\
\text { tolerance) }\end{array}$ & Continuous & & $\begin{array}{l}\text { A count of native floristic regions (based on } \\
\text { Takhtajan 1886) }\end{array}$ \\
\hline $\begin{array}{l}\text { Number of native } \\
\text { kingdoms (proxy for } \\
\text { environmental tolerance) }\end{array}$ & Continuous & & $\begin{array}{l}\text { A count of native kingdoms (based on } \\
\text { Takhtajan 1886) }\end{array}$ \\
\hline $\begin{array}{l}\text { Number of introduced } \\
\text { regions (proxy for } \\
\text { popularity in horticulture) }\end{array}$ & Continuous & & $\begin{array}{l}\text { A count of introduced floristic regions } \\
\text { (based on Takhtajan 1886) }\end{array}$ \\
\hline Residence time & Continuous & & $\begin{array}{l}\text { Years (calculated as the time elapsed } \\
\text { between the earliest recorded year in the } \\
\text { introduced region or earliest year of } \\
\text { publication and the year 2017) }\end{array}$ \\
\hline Disturbed habitat $\times$ light & Interaction & & $\begin{array}{l}\text { To determine if light availability influences } \\
\text { a fern's occurrence in disturbed habitat) }\end{array}$ \\
\hline $\begin{array}{l}\text { Number of introduced } \\
\text { regions } \times \text { life form }\end{array}$ & Interaction & & $\begin{array}{l}\text { To consider the types of life forms that are } \\
\text { more widely introduced ( popularity in } \\
\text { horticulture) }\end{array}$ \\
\hline $\begin{array}{l}\text { Mode of regeneration } \times \\
\text { wet habitat }\end{array}$ & Interaction & & $\begin{array}{l}\text { To consider the importance of water in fern } \\
\text { reproduction }\end{array}$ \\
\hline
\end{tabular}


Table 2. Variables retained by stepwise backwards logistic regression $(P<0.10)$ for significantly influencing the probability of an alien fern species to transition from introduced to naturalised (transition one), naturalised to invasive (transition two), or introduced to invasive (transition three)

\begin{tabular}{|c|c|c|c|c|c|}
\hline & Dev & $P$ value & & Estimate & SE \\
\hline \multicolumn{6}{|l|}{ Transition one } \\
\hline Intercept & & & & 0.041 & 0.768 \\
\hline Mode of regeneration $^{a}$ & 7.556 & $0.006 * *$ & & 1.803 & 0.704 \\
\hline Number of introduced regions & 2.911 & 0.088 & & 0.627 & 0.571 \\
\hline \multicolumn{6}{|l|}{ Transition two } \\
\hline Intercept & & & & -4.648 & 1.647 \\
\hline Number of introduced regions & 19.875 & $8.267 \mathrm{e}-06 * * *$ & & 0.320 & 0.105 \\
\hline \multirow{3}{*}{ Light ${ }^{b}$} & 12.250 & $0.007 * *$ & All: & 2.596 & 0.970 \\
\hline & & & Semi-shade: & 0.838 & 0.852 \\
\hline & & & Sun: & 1.057 & 0.963 \\
\hline Life form ${ }^{c}$ & 3.579 & 0.059 & & 2.410 & 1.386 \\
\hline Disturbed habitat ${ }^{\mathrm{d}}$ & 3.091 & 0.079 & & 0.771 & 0.439 \\
\hline \multicolumn{6}{|l|}{ Transition three } \\
\hline Intercept & & & & -4.450 & 1.160 \\
\hline Number of introduced regions & 18.956 & $1.337 \mathrm{e}-05 * * *$ & & 0.305 & 0.108 \\
\hline \multirow[t]{3}{*}{ Light $^{b}$} & 12.678 & $0.005 * *$ & All: & 2.912 & 1.051 \\
\hline & & & Semi-shade: & 1.273 & 0.974 \\
\hline & & & Sun: & 1.910 & 1.080 \\
\hline Disturbed habitat ${ }^{\mathrm{d}}$ & 3.885 & $0.049 *$ & & 0.929 & 0.465 \\
\hline Number of native kingdoms & 4.048 & $0.044 *$ & & 0.435 & 0.236 \\
\hline Mode of regeneration ${ }^{\text {a }}$ & 4.399 & $0.036 *$ & & 0.947 & 0.465 \\
\hline
\end{tabular}

${ }^{a}$ The reference level included in the intercept is sexual or vegetative reproduction only; the estimate displayed is for a species displaying both modes of regeneration.

${ }^{b}$ The reference level included in the intercept is shade; the estimate displayed is for all types of light, semi-shade and sun.

c The reference level included in the intercept is epiphyte or lithophyte; the estimate displayed is for geophytic species.

$\mathrm{d}$ The reference level included in the intercept is for a species showing preference for undisturbed habitat; the estimate displayed is for a species showing preference for disturbed habitat. 
Click here to access/download Supplementary Material Supplementary_1_E_J_Jones_2018.xlsx 
Click here to access/download Supplementary Material Supplementary_2_E_J_Jones_2018.xlsx 


\section{A global assessment of terrestrial alien ferns (pteridophyta) and traits associated with invasiveness}

Emily J. Jones ${ }^{\mathrm{a}}$, Tineke Kraaij ${ }^{\mathrm{b}}$, Herve Fritz ${ }^{\mathrm{c}}$, Desika Moodley ${ }^{\mathrm{d}}$

aNelson Mandela University; Madiba Dr, George Central, George, 6530, South Africa, Invasive Species Programme, South African National Biodiversity Institute,; s216016479@mandela.ac.za, +27823040264, ORCID 0000-0003-0008-6580

bNelson Mandela University; Madiba Dr, George Central, George, 6530, South Africa, Tineke.Kraaij@mandela.ac.za, +27448015018, ORCID 0000-0002-8891-2869

'Herve Fritz: Université Lyon, CNRS, UCBL, UMR 5558, Villeurbanne, 69622, France. Nelson Mandela University; SRU, Madiba Dr, George Central, George, 6530, South Africa, herve.fritz@univ-lyon1.fr, +2768041292, ORCID 0000-0002-7106-3661

${ }^{\mathrm{d}}$ Desika Moodley: Department of Invasion Ecology, Institute of Botany, Academy of Sciences of the Czech Republic, Průhonice CZ 252 43, Czech Republic, desikamoodley29@gmail.com, +420739294540

\section{$\underline{\text { Acknowledgements }}$}

This work was supported by the South African National Department of Environment Affairs through its funding of the South African National Biodiversity Institute Invasive Species Programme and by Nelson Mandela University. We thank Ronel Klopper whom extracted relevant data from the PRECIS database, and Neil Crouch for his invaluable advice and guidance 